\title{
Fe Thiolate Complexes Catalyst in Photocatalysis System for Hydrogen Production from Water Xiao-Xin YANG ${ }^{1, a}$,Da-Tian FU ${ }^{2, b}$ and Xiu-Lan CAI* \\ 1 Guangdong Pharmaceutical University, Guangzhou, China \\ 2 Hainan Cancer Hospital, Haikou, China

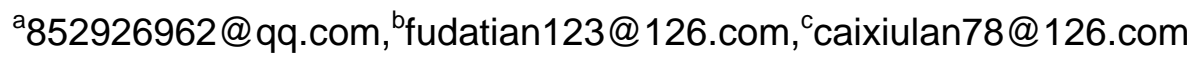 \\ ${ }^{*}$ Corresponding author
}

Keywords: Fe thiolate complexes; Photocatalysis System; Hydrogen

\begin{abstract}
Fe thiolate complexes Fe(bpy)(pyS) ${ }_{2}(\mathrm{M})$ were synthesized, the properties of complexes were characterized by ${ }^{1} \mathrm{H}-\mathrm{NMR}$ and MS and the effects of reaction conditions on catalytic performance had been studied. The results indicated that when the $\mathrm{pH}$ value of catalysis system was 11.6, ethanol/water was used as solvent and the volume ratio of ethanol/water was $1: 1$, catalyst $\mathrm{M}$ showed the best catalytic performance and hydrogen production was $56.3 \mu \mathrm{mol} / \mathrm{h}$ after reacted for $15 \mathrm{~h}$.
\end{abstract}

\section{Introduction}

Fossil fuels has been the most important energy sources in the fields of transportation and production[1-3].Water as a kind of renewable clean energy, is being widely research. In the past few decades, hydrogen generation from water under solar as a kind of economic and sustainable method gets widely attention. A homogeneous photocatalysis system consists of a light-harvesting photosensitizer, a sacrificial electron donor and a proton-reduc-tiom catalyst. In this system, the catalyst showed higher catalytic activity. Therefore, the homogeneous hydrogen generation were constructed in recent years[4-6].

In the past few years, noble metal complexes were used as catalysts in hydrogen production, such asPt, Pd and Rh[4-6]. Cheaper catalysts(such as cobalt, iron and nickel) for photochemical hydrogen production were more economical. Recently, a homogeneous photocatalytic system mad up of $\left[\mathrm{Co}(\mathrm{bpy})_{3}\right] \mathrm{Cl}_{2}$ were reported by Wang et al[11].The $\mathrm{H}_{2}$ generation of TON number is 207.6 and $\mathrm{H}_{2}$ generation rate of TON number is 54 .

In this paper, a new noble-metal-free complex $\mathrm{Fe}(\mathrm{bpy})(\mathrm{pyS})_{2}(\mathrm{M})$ was synthesized. The properties of complexes were characterized by ${ }^{1} \mathrm{H}-\mathrm{NMR}$ and $\mathrm{MS}$ and the effects of reaction conditions on catalytic performance had been studied.

\section{Experimental}

\subsection{Reagents and Instruments}

All reactions were carried out under $\mathrm{N}_{2}$ atmosphere with standard Schlenk techniques. Solvents were dried with $4 \AA$ molecular sieves and distilled prior to be used according to the standard methods. 2,2'-bipyridine, 1,10-phenanthroline hydrate, Cobalt nitrate hexahydrate, Manganese acetate tetrahydrate, sodium metal, fluoresce in (Fl) and triethylamine (TEA) were purchased from Aldrich and used without further purification.

\subsection{Synthesis of Fe (bpy)(pyS)}

$\mathrm{Fe}(\mathrm{bpy})(\mathrm{pyS})_{2}(\mathrm{M})$ was synthesized as Fig. 1 . The solution of 2,2'-bipyridine $(1.0 \mathrm{~g}, 6.4 \mathrm{mmol})$ in 10 $\mathrm{mL}$ of acetonitrile was added slowly to the solution containing $\mathrm{FeCl}_{3}\left(\mathrm{H}_{2} \mathrm{O}\right)_{6}(1.7 \mathrm{~g}, 6.4 \mathrm{mmol})$ in 80 $\mathrm{mL}$ of acetonitrile over $30 \mathrm{~min}$. The color of the above solution changed from light violet to dark violet. Then a solution containing pySH (1.42 g, $12.9 \mathrm{mmol})$ and TEA (2.2 mL, $16.0 \mathrm{mmol})$ in 30 $\mathrm{mL}$ of acetonitrile was added to above mixed solution slowly over $1 \mathrm{~h}$. The solution turned brown, 
and a brown precipitate formed after stirring for another $8 \mathrm{~h}$. The product (M) was collected by suction filtration. The products were stored under atmosphere without protection from water and oxygen. The yield of $\mathrm{M}$ was $1.7 \mathrm{~g}(74 \%) .{ }^{1} \mathrm{H}-\mathrm{NMR}\left(\mathrm{CDCl} 3,20^{\circ} \mathrm{C}\right): \delta 8.7,8.18,7.48 \mathrm{ppm}$. ESI MS: m/z 432.02 (expected), 432.02 (found). Elem. Anal. Calculated: C, 55.56; H, 3.73; N, 12.96; Found: C, 55.54; H, 3.76; N, 12.95 .

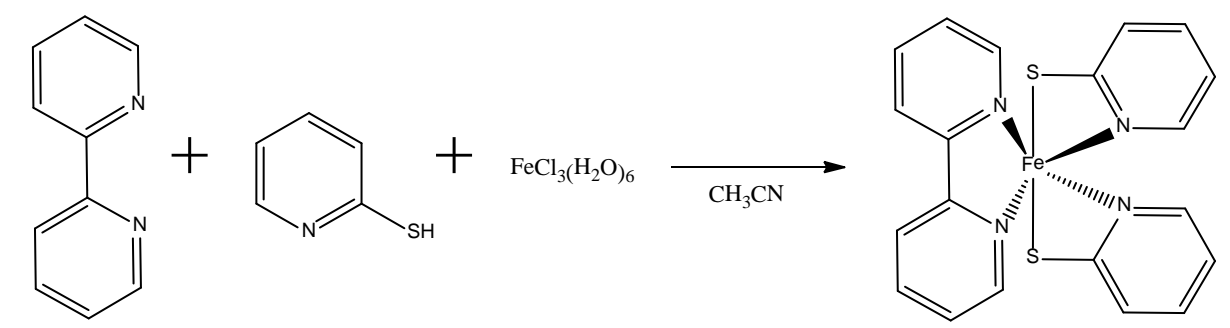

Fig. 1 The synthetic routes of $M$

\section{3 ${ }^{1} \mathrm{H}$-NMR Spectra}

${ }^{1}$ H-NMR spectra were collected on Varian INOVA 400NMR spectrometer.

\subsection{Mass Spectra}

Mass spectra were performed by electrospray ionization (ESI) on HP 1100 MSD instrument.

\subsection{Evaluation of Performance of Photocatalyst for Hydrogen Production}

The $0.04 \mathrm{mM}$ photocatalysts was placed in the solution containing ethanol/ $\mathrm{H}_{2} \mathrm{O}\left(1: 1_{\mathrm{v} / \mathrm{v}} 120 \mathrm{~mL}\right), 2.0$ $\mathrm{mM} \mathrm{Fl}$ and TEA (5\% v/v). The above solution was place in an inner irradiation quartz cell (250 mL) and protected from light before use. The $\mathrm{pH}$ values of the solutions were measured with $\mathrm{pH}$ meter and adjusted to 11.6 by adding $\mathrm{HCl}$ or $\mathrm{NaOH}$. The photocatalysis system were kept at $25{ }^{\circ} \mathrm{C}$. The cell were irradiated with a $500 \mathrm{~W}$ Xe lamp and the produces were analyzed with an on-line TCD gas chromatograph (GC-9800). During the irradiation process, $0.5 \mathrm{~mL}$ methane was used as the internal standard gas, and the amount of hydrogen was calculated according to the amount of methane.

\section{Results and discussion}

The results of previous studies indicated that the main influencing factors on performance of photocatalytic system for hydrogen production were the $\mathrm{pH}$ value and solvent of the system. In this paper, the effects of $\mathrm{pH}$ value and solvent of the system on the performance of catalyst $\mathrm{M}$ were investigated and the optimum conditions for hydrogen production were determined.

\subsection{The Effects of pH Value on the Performance of Catalyst $M$ for Hydrogen Production}

Fluoresce in $(2.0 \mathrm{mM})$, catalyst $(0.04 \mathrm{mM})$ and triethylamine $(5 \%)$ were added to the reactor and ethanol/water $(\mathrm{V} / \mathrm{V}, 1: 1)$ was used as solvent. In this reaction, the intensity of light, temperature and stirring speed remained constant for $15 \mathrm{~h}$. The effects of different $\mathrm{pH}$ value $(9,10,11,12,13)$ of reaction system on catalytic performance of catalyst $M$ were investigated and the experimental results were shown in Fig. 2. 


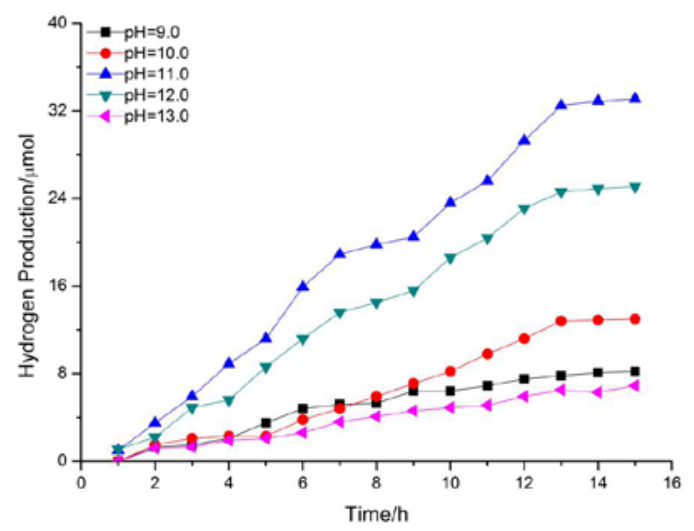

Fig. 2 Effects of $\mathrm{pH}$ value (changed from 9, 10, 11, 12 to 13) on the performance of catalyst M for hydrogen production

The results of Fig. 2 showed that with the increasing of reaction time, the catalytic performance of $\mathrm{M}$ presented an increasing trend which indicated that catalyst $\mathrm{M}$ need time to be activated and the activation time was different with different $\mathrm{pH}$ values.

In the same reaction time, catalytic performance of catalyst $M$ showed an increasing trend and then decreased with the increasing of $\mathrm{pH}$ value of solution. When the value of $\mathrm{pH}$ was 11, catalyst $\mathrm{M}$ showed the highest photocatalytic performance and hydrogen production of $\mathrm{M}$ reached 33.1 $\mu \mathrm{mol}$. When the $\mathrm{pH}$ value was 13 , a rapid decrease in the amount of hydrogen production occurred and the hydrogen production of catalyst $M$ was reduced to $25.1 \mu \mathrm{mol}$ after reacted for $15 \mathrm{~h}$.

According to the results above analysis, it was indicated that the catalytic performance of catalyst $\mathrm{M}$ was obviously affected by $\mathrm{pH}$ value of reaction system. Therefore, it was a very meaningful work to optimize and determine the most suitable $\mathrm{pH}$ value of this system. The effects of $\mathrm{pH}$ value (changed from 11.2, 11.4, 11.6 to 11.8) on catalytic performance of catalyst M had been researched and the experimental results were showed in Fig. 3.

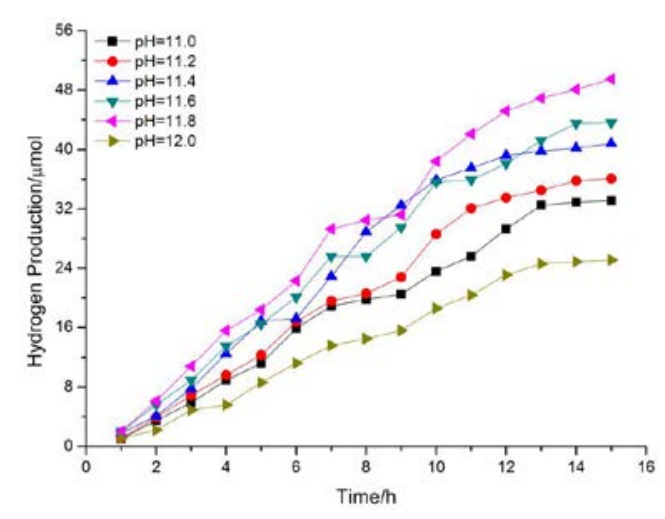

Fig. 3 Effects of $\mathrm{pH}$ value (changed from 11.2, 11.4, 11.6 to 11.8) on the performance of catalyst $\mathrm{M}$ for hydrogen production

The results of Fig. 3 indicated that catalyst $\mathrm{M}$ presented the best catalysis performance when $\mathrm{pH}$ value was 11.6 and the amount of hydrogen production reached $49.5 \mu \mathrm{mol}$ after reacted for $15 \mathrm{~h}$. Therefore, the suitable $\mathrm{pH}$ value of this catalytic reaction system was 11.6.

\subsection{The Effects of Solvents on the Performance of Catalyst $M$ for Hydrogen Production}

Fluoresce in $(2.0 \mathrm{mM})$, catalyst $(0.04 \mathrm{mM})$ and triethylamine (5\%) were added to the reactor. In the 
process of reaction, the intensity of light, temperature and stirring speed remained constant for $15 \mathrm{~h}$. The effects of different solvents (ethanol/water, methanol/water, acetonitrile/water, ethanol, water) on catalytic performance of catalyst $\mathrm{M}$ were investigated and the experimental results were shown in Fig. 4.

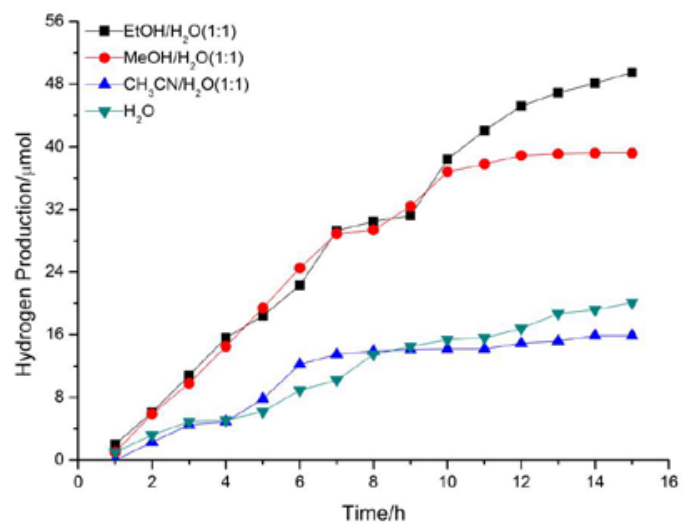

Fig. 4 The effects of solvents on the performance of catalyst $M$ for hydrogen production

Fig. 4 indicated that the catalytic performances of catalyst $M$ were obviously affected by the type of solvents in this reaction system. When the solvent of this system was ethanol/water, catalyst $\mathrm{M}$ showed the best catalysis performance and hydrogen production of catalyst $\mathrm{M}$ was $49.5 \mu \mathrm{mol}$ after reacted for $15 \mathrm{~h}$. When the solvent was acetonitrile/water or pure water, catalyst $\mathrm{M}$ showed poor catalytic performance. When pure ethanol was used as solvent, there was no hydrogen. The results above were mainly because that the interaction between solubility and electrostatic of solvent had a great influence on hydrogen production. In this reaction system, the proton was provided by water and the role of ethanol was to improve the solubility of catalyst and fluorescence but could not provide proton. According to above analysis, it was determined that the suitable solvent for this catalytic system was ethanol/water.

3.3 The Effects of Different Ratio (Ethanol/Water) on the Performance of Catalyst $M$ for Hydrogen Production

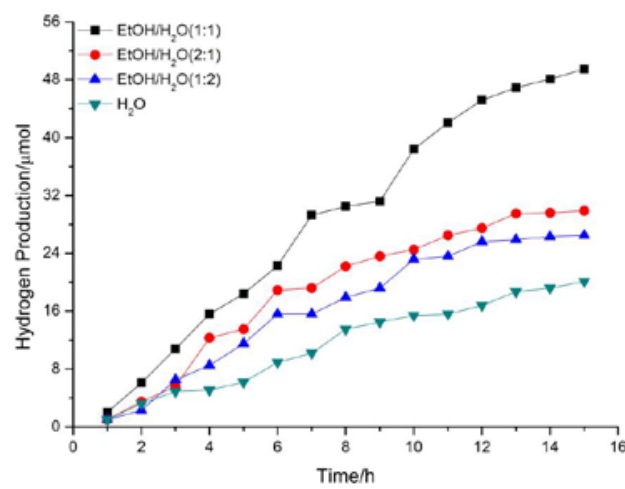

Fig. 5 The effects of different ratio (ethanol/water) on performances of catalyst $\mathrm{M}$ for hydrogen production

The effects of different ratio of ethanol/water on the catalytic performance of catalyst $\mathrm{M}$ for hydrogen production were investigated and the experimental results were showed in Fig. 5. 
Fig. 5 presented that when the volume ratio of ethanol/water was1:1, catalyst $\mathrm{M}$ showed the highest catalytic performance and hydrogen production was $52.3 \mu \mathrm{mol}$ after reacted for $15 \mathrm{~h}$. When the volume ratio was $2: 1$ or $1: 2$, the catalytic performance of catalyst decreased. Therefore, the suitable volume ratio of ethanol/water was 1:1.

\subsection{Study on the Life of Catalyst System under the Optimum Reaction Conditions}

Under the optimum reaction conditions, the life of catalyst $\mathrm{M}$ was studied and the experimental result was shown in Fig. 6.

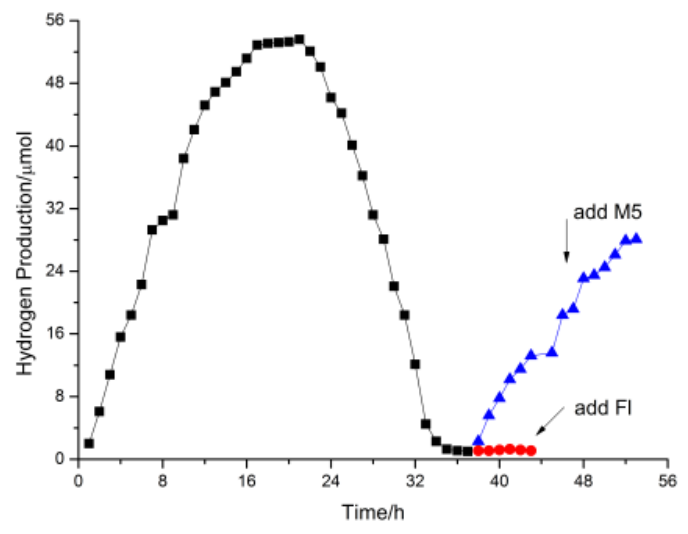

Fig. 6 Study on the life of catalyst system under the optimum reaction conditions

Fig. 6 displayed that under the optimum reaction conditions, the life of catalyst $\mathrm{M}$ was $32 \mathrm{~h}$ and the highest hydrogen production was $56.3 \mu \mathrm{mol}$.

Fluoresce in was added into the deactivated system to research the reason of deactivation of catalyst. Results of Fig. 6 showed there was no hydrogen produced again which indicated that the proton reduction was mainly due to the loss of catalyst activity.

\section{Conclusions}

Thiolate complexes Fe(bpy)(pyS) $)_{2}(\mathrm{M})$ had been synthesized and the performances of complexes $\mathrm{M}$ were studied. The results indicated Febalt thiolate complexes $M$ was active for light-driven hydrogen production in aqueous/organic mixtures and the hydrogen production of $\mathrm{M}$ was 52.3 $\mu \mathrm{mol} / \mathrm{h}$ after reacted for 15 hours when the $\mathrm{pH}$ value of was 11.6 , ethanol/water used as solvent and volume ratio of ethanol/water was1:1. under the optimum reaction conditions, the life of catalyst $\mathrm{M}$ was $32 \mathrm{~h}$ and the highest hydrogen production was $56.3 \mu \mathrm{mol}$. The result also indicated that the proton reduction was mainly due to the loss of catalyst activity.

\section{Acknowledgments}

This work was supported by the National Natural Science Foundation of China (21106022), Science and Technology Planning Project of Guangdong Province, China (2013B010404045) and Educational Commission of Guangdong Province, China (Yq2013100).

\section{References}

[1] Mann M E, Bradley R S, Hughes M K. Global-scale temperature patterns and climate forcing over the past six centuries[J]. Nature, 1998, 392(6678): 779-787.

[2] Mann M E, Bradley R S, Hughes M K, et al. Global temperature patterns[J]. Science, 1998, 280(5372): 2027-2027. 
[3] Christensen J H, Hewitson B, Busuioc A, et al. Regional climate projections[J]. Climate Change, 2007: The Physical Science Basis. Contribution of Working group I to the Fourth Assessment Report of the Intergovernmental Panel on Climate Change, University Press, Cambridge, Chapter 11, 2007: 847-940.

[4] Bard A J, Fox M A. Artificial photosynthesis: solar splitting of water to hydrogen and oxygen[J]. Accounts of Chemical Research, 1995, 28(3): 141-145.

[5] Fihri A, Artero V, Razavet M, et al. Cobaloxime-Based Photocatalytic Devices for Hydrogen Production[J]. Angewandte Chemie, 2008, 120(3): 574-577.

[6] Rau S, Walther D, Vos J G. Inspired by nature: light driven organometallic catalysis by heterooligonuclear Ru (II) complexes[J]. Dalton Transactions, 2007 (9): 915-919.

[7] Wang M, Na Y, Gorlov M, et al. Light-driven hydrogen production catalysed by transition metal complexes in homogeneous systems[J]. Dalton Transactions, 2009 (33): 6458-6467.

[8] Stoll T, Gennari M, Serrano I, et al. [RhIII (dmbpy) 2Cl2]+ as a Highly Efficient Catalyst for Visible-Light-Driven Hydrogen Production in Pure Water: Comparison with Other Rhodium Catalysts[J]. Chemistry-A European Journal, 2013, 19(2): 782-792.

[9] Ortmans I, Didier P, Kirsch-De Mesmaeker A. New Charge Transfer Luminescent Polymetallic Complexes of Rhodium(III), Iridium(III), and Ruthenium(II) with the Bridging Ligand 1, 4, 5, 8, 9, 12-Hexaazatriphenylene[J]. Inorganic Chemistry, 1995, 34(14): 3695-3704.

[10] Elvington M, Brewer K J. Photoinitiated electron collection at a metal in a rhodium-centered mixed-metal supramolecular complex[J]. Inorganic Chemistry, 2006, 45(14): 5242-5244.

[11] Dong J, Wang M, Zhang P, et al. Promoting effect of electrostatic interaction between a cobalt catalyst and a xanthene dye on visible-light-driven electron transfer and hydrogen production[J]. The Journal of Physical Chemistry C, 2011, 115(30): 15089-15096. 